\title{
The Epidemiology of Hospitalized Head Injury in British Columbia, Canada
}

\author{
Leah A. Phillips, Don C. Voaklander, Colleen Drul, Karen D. Kelly
}

\begin{abstract}
Objective: This descriptive study seeks to identify the incidence rates of head injuries in a large Canadian province, given incident cases for a ten year period. It describes cases in terms of age standardized rates, demographics, and health care utilization. Methods: The analyses were done using descriptive statistics. Incidence rates were calculated using the direct method. The indicators of hospital resource utilization were: mean length of hospital stay, number of intensive care unit (ICU) stays, and mean length of stay in an ICU. Results: In the ten year period, British Columbia saw 48,753 admissions due to an incident head injury. The most common head injury diagnosis was an "Intracranial" injury. The year with the highest total age standardized rate was 1991/92 (174.18/100 000). The mean length of hospital stay was 7.4 days. Ten percent had an ICU stay and the mean length of stay was 4.4 days ( \pm 4.8$)$. The diagnosis with the longest mean length of stay was a "Fractured Skull" while of the top five E-code categories; "Motor Vehicle Traffic" had the highest mean length of stay with 12.2 days. Conclusions: Our study provides a much needed analysis of the incidence of head injuries in British Columbia. These rates can be compared to other provinces using the 2001 Canadian population as the standardized population. Our results indicate that there are certain "at risk" groups that warrant attention, in particular, younger men with lower socioeconomic standing. Indicators of health care utilization presented in the study should generate policy discussions.
\end{abstract}

RÉSUMÉ: Épidémiologie du traumatisme crânien nécessitant une hospitalisation en Colombie-Britannique, au Canada. Objectif : Le but de cette étude descriptive était de préciser le taux d'incidence des traumatisme crâniens dans une grande province canadienne à partir des cas incidents survenus au cours d'une période de dix ans. Nous décrivons les taux standardisés pour l'âge, les caractéristiques démographiques et l'utilisations des services de santé. Méthodes: Les données ont été analysées au moyen de méthodes statistiques descriptives. Les taux d'incidence ont été calculés par méthode directe. Les indicateurs d'utilisation de ressources hospitalières étaient les suivants: la durée moyenne d'hospitalisation, le nombre d'hospitalisations à l'unité de soins intensifs (USI) et la durée moyenne du séjour dans une USI. Résultats : Au cours d'une période de dix ans, on a dénombré 48753 admissions pour un traumatisme crânien incident en Colombie-Britannique. Le diagnostic de traumatisme à la tête le plus fréquent était «traumatisme intracrânien». L'année où le taux total standardisé pour l'âge était le plus élevé était 1991/92 (174,18 / 100 000). La durée moyenne d'hospitalisation était de 7,4 jours, $10 \%$ avaient séjourné à l'USI et la durée moyenne du séjour était de 4,4 jours ( $\pm 4,8)$. Le diagnostic qui comportait le séjour moyen le plus long était «fracture du crâne » et parmi les 5 catégories de causes externes de blessures (E-code) les plus fréquentes selon la CIM « accident de la route » comportait le séjour moyen le plus long, soit 12,2 jours. Conclusions : Cette étude présente une analyse de l'incidence des traumatismes crâniens en Colombie-Britannique. Ces taux peuvent être comparés à ceux des autres provinces en utilisant comme population de référence la population canadienne en 2001. Nos résultats indiquent qu'on doit porter une attention particulière à certains groupes « à risque », surtout les hommes jeunes dont le statut socioéconomique est faible. Les indicateurs d'utilisation des services de santé présentés dans cette étude devraient susciter des discussions sur la conception de politiques concernant les traumatismes crâniens.

Can. J. Neurol. Sci. 2009; 36: 605-611

The Centre for Disease Control defines a traumatic brain injury (TBI) as an injury caused by a blow or jolt to the head or a penetrating injury that disrupts the normal function of the brain. ${ }^{1}$ Traumatic brain injury is cited as a leading cause of disability and survivors of this type of injury often suffer from long term cognitive, mood, and behavioral disorders. A mild traumatic brain injury may cause symptoms such as a brief change in mental status or consciousness, whereas a more severe injury can mean a person experiences a loss of consciousness for an extended period of time or amnesia after the injury. ${ }^{2,3}$ There is little research in Canada that indicates the extent of incidence or disability caused by either mild or severe TBI. Additionally, there appears to be vast differences in the estimates for the incidence of TBI both in Canada and throughout the world. For example, one study from the United Kingdom (UK) indicated an annual incidence rate for TBI of 297 per 100 000, whereas another European study indicated an incidence rate of only 7.3 per $100000 .^{4,5}$ In North America, one cohort study looking only at severe TBI in a large provincial health region in Canada found an incidence rate of 11.4 per $100000^{6}$ whereas, the Centers for

From the Alberta Centre for Injury Control \& Research (LAP, DCV, CD), School of Public Health, Faculty of Nursing (KDK), University of Alberta, Edmonton, Alberta, Canada.

Received October 22, 2008. Final Revisions Submitted April 30, 2009. Correspondence to: Leah A. Phillips, School of Public Health, University of Alberta, 4075 RTF, 8308-114st, Edmonton, Alberta, T6G 2E1, Canada. 
Disease Control in the United States (US) reports a hospitalization rate of 99 per 100,000. These discrepancies are likely due to differences in the definition of TBI and the data sources used.

The goal of this study is to describe the epidemiology of TBI, using hospital admission information from a large Canadian province with a population of 4.3 million. Incident cases of TBI for a ten year period will be described in terms of age standardized rates, demographics, and health care utilization during the acute phase of injury.

\section{METHODS}

This study is a population based surveillance cohort from the province of British Columbia (BC), Canada. This study uses a descriptive epidemiologic design, using data derived from a cohort of patients admitted to hospital in the province of BC in the fiscal years of 1991/92-2000/01. British Columbia is the third largest province in Canada. The information pertaining to all hospitalizations in the province are captured and maintained by two databases in the province of $\mathrm{BC}$, and are the source for the data in this study:

(1) Canadian Institute of Health Information (CIHI) Disharge Abstract Data System - These abstracts include International Classification of Diseases, Version 9 (ICD9) diagnostic codes (up to 16), ICD-9 external cause of injury (E-codes), age, sex, admission, and discharge dates. One hundred percent of hospitalizations in BC are captured through this system.

(2) BC Health Insurance Registration File - This file includes demographic information for each person registered with the BC Ministry of Health. Health insurance coverage is universal in Canada. Probabilistic data linking of these data was conducted by the Centre for Health Services and Policy Research at the University of British Columbia. The Centre for Health Services and Policy Research maintains a data warehouse of all administrative health data collected in BC.

Hospitalization data were collected using service provision records that include summary diagnostic data coding according to the International Classification of Diseases, 9th revision (ICD9). For this study, only cases with valid provincial health care numbers were included in the cohort regardless of where their injury occurred (e.g. outside the province). People injured in the province of $\mathrm{BC}$ who were not residents of the province are not included in the data.

\section{Case Definition}

All the patients in the cohort were admitted and treated for a 'head injury' (including both major and minor traumatic brain injuries) at a BC hospital. Head injuries were defined using a consensus reached between three sets of administrative case ascertainment criteria (CIHI, Center for Disease Control (CDC) in Atlanta, Georgia, and the Barell Matrix). The CDC recommends using the diagnostic ICD-9 codes in the ranges of 800.0-801.9, 803.0-804.9 and 850.0-854.1 and for cases resulting in death $873.0-873.9,905.0$ and $907.0 .^{7}$ This definition is concurrent with the CIHI definitional codes.

All head injury cases were identified in this study using the following codes (with some exceptions noted) and definitions and are labeled as such in Table 1: 800.0-801.9 "Fx Skull" (including fractures of the vault or base of the skull-closed and open with hemorrhage), 803.0-804.9 "Other Skull Fxs" (including unqualified and multiple fractures of the skull), 850.0854.1 "Intracranial" (including concussion, contusion, laceration, and subarachnoid, subdural and extradural hemorrhage-following injury), 950.1-950.3 "Blood Vessels and Nerves" (these included injuries to the optic chiasm, optic pathways, and visual cortex), 959.01 "Head Injury, NOS" (this category is a category of exclusion, therefore it excludes injury to the blood vessels, eye, internal organs, intracranial sites, nerves, spinal cord, and concussion). Cases are coded "NOS" if there is inadequate information as to other more specific codes. Cases were included if coded 873.0-873.9 (open wounds to the head), 905.0 and 907.0 (fractured skull and facial bones) only if they resulted in death; none of these cases were noted in the data.

The choice of these codes is consistent with the standardized data definition for Traumatic Brain Injury by the CDC and is consistently used as a case definition in the existing research literature on the incidence of TBI. It is also consistent with the definition used by CIHI which uses the same codes to define head injury cases..$^{7-12}$

Once this definition was established, cases were included if any one of the defined codes appeared within any of the 16 diagnostic fields. In cases where an individual had more then one IDC-9 code indicating a head injury, we used a hierarchy that selected the code with the greatest severity as the primary diagnosis. This hierarchy of severity of injury was based on the use of the Barell Injury Diagnosis Matrix. Within the matrix, injuries to the head and neck are categorized as either a Traumatic Brain Injury (Types 1, 2, or 3) or other injuries of the head/face based on severity with Type 1 injuries being the most severe (eg: intracranial injury). ${ }^{13}$ To ensure the traumatic nature of all the injuries in this study we only accepted head injury cases where there was a clear Nature of Injury Code (E-code) attached to the injury that was consistent with traumatic injury.

Indicators for utilization of hospital resources for head injured patients were examined for the ten year period. These included the mean length of hospital stay, admission to an intensive care unit (ICU), and mean length of stay in an ICU.

The hospital length of stay reflects the actual time in days a patient spent in hospital. This time includes the stay in the emergency room, the transfer to a hospital unit and is inclusive until he or she was discharged from the hospital. Determination of an ICU admission was based on the presence of an ICU service code. The intensive care unit (ICU) service code does not discriminate been types of ICU.

All analyses were performed using SPSS $®$ version 16 and STATA $®$ SE version 9. Missing values in the data were not replaced. Extreme outliers for length of hospital stay were defined as three standard deviations from the mean and were excluded in subsequent analyses.

The analyses were done using standard descriptive statistics and univariate correlations and the significances of differences were tested using Chi-square for nominal variables and T-Test or analysis of variance (ANOVA) for continuous variables. A p $<$ 0.05 was considered statistically significant.

To allow for annual incident rate comparisons, the direct method was used to calculate standardized rates. The direct method for standardization controls for potential sources of bias 
Table 1: Demographics of head injury hospital admissions, British Columbia (1991-2001)

\begin{tabular}{|c|c|c|}
\hline Variable & $\mathbf{N}$ & $\%$ of total \\
\hline \multicolumn{3}{|l|}{ Gender } \\
\hline Male & 33471 & 68.7 \\
\hline Female & 15165 & 31.1 \\
\hline \multicolumn{3}{|l|}{ Age $(\mu=34.3 \pm 23.0)$} \\
\hline $0-16$ years & 11384 & 23.4 \\
\hline $17-55$ & 28282 & 58.0 \\
\hline $56+$ & 8896 & 18.2 \\
\hline \multicolumn{3}{|l|}{$\begin{array}{l}\text { Year of Admission } \\
\text { (fiscal year) }\end{array}$} \\
\hline $1991 / 92$ & 5798 & 11.9 \\
\hline $1992 / 93$ & 5449 & 11.2 \\
\hline $1993 / 94$ & 5560 & 11.5 \\
\hline $1994 / 95$ & 5375 & 11.0 \\
\hline 1995/96 & 5237 & 10.7 \\
\hline 1996/97 & 4922 & 10.1 \\
\hline $1997 / 98$ & 4823 & 9.9 \\
\hline $1998 / 99$ & 4437 & 9.1 \\
\hline 1999/00 & 3569 & 7.3 \\
\hline $2000 / 01$ & 3535 & 7.3 \\
\hline \multicolumn{3}{|l|}{ Discharge Status } \\
\hline Alive & 46634 & 95.7 \\
\hline Dead & 2119 & 4.3 \\
\hline \multicolumn{3}{|l|}{ Diagnosis Category } \\
\hline $\begin{array}{c}\text { Intracranical (850.0-854.1) } \\
\text { - Intracranical NOS }\end{array}$ & $\begin{array}{l}25569 \\
\cdot \quad 11779\end{array}$ & $\begin{array}{rr}52.4 & \\
\cdot & 45.0\end{array}$ \\
\hline $\begin{array}{ll} & (854.0-854.1) \\
\text { - Concussion (850.0) }\end{array}$ & - 8925 & - 34.9 \\
\hline $\begin{array}{l}\text { Fx Facial Bones (802.0- } \\
802.9,830.0)\end{array}$ & 15595 & 32.0 \\
\hline Fx Skull (800.0-801.9) & 5075 & 10.4 \\
\hline Head Injury NOS (959.01) & 1461 & 3.0 \\
\hline $\begin{array}{l}\text { Other Skull Fxs (803.0- } \\
804.9)\end{array}$ & 855 & 1.8 \\
\hline $\begin{array}{l}\text { Blood Vessels and Nerves } \\
\text { (including Optic) }(900.0- \\
900.9,950.1-950.3,953.0- \\
953.9)\end{array}$ & 198 & .04 \\
\hline \multicolumn{3}{|l|}{ Ecode Category } \\
\hline Falls & 15143 & 31.1 \\
\hline Motor Vehicle Traffic & 12725 & 26.1 \\
\hline Intentional/Violence & 8677 & 17.8 \\
\hline Other & 7096 & 14.6 \\
\hline Other Road & 2587 & 5.3 \\
\hline Motor Vehicle Nontraffic & 954 & 2.0 \\
\hline Adverse Events/Poisoning & 375 & 0.8 \\
\hline Fire/Nat/Suff/Drowning & 347 & 0.7 \\
\hline Transport (Air/Water) & 342 & 0.7 \\
\hline Suicide & 309 & 0.6 \\
\hline Legal/Underter/War & 137 & 0.3 \\
\hline Missing & 10 & 0.0 \\
\hline \multicolumn{3}{|l|}{ Socioeconomic Quintile } \\
\hline Lowest & 11244 & 23.1 \\
\hline Low & 9573 & 19.6 \\
\hline Middle & 8637 & 17.7 \\
\hline High & 8587 & 17.6 \\
\hline Highest & 7885 & 16.2 \\
\hline Unknown & 2827 & 5.8 \\
\hline \multicolumn{3}{|l|}{ Health Authority } \\
\hline Fraser & 13048 & 26.8 \\
\hline Interior & 10543 & 21.6 \\
\hline Vancouver Island & 9008 & 18.5 \\
\hline Vancouver Coastal & 8953 & 18.4 \\
\hline Northern & 6815 & 14.0 \\
\hline Unknown & 3860 & .8 \\
\hline
\end{tabular}

$\mathrm{N}=48753 ; \mathrm{Fx}=$ Fractured/Fractures; NOS=Not Otherwise Specified. resulting from variation in age distribution. The population at risk for each year was the British Columbia population and the standardized population for this study was the 2001 Canadian population.

\section{RESULTS}

The descriptive epidemiologic analysis indicates that in the ten year period, (1991/92-2000/01, fiscal years) British Columbia hospitals saw 48,753 admissions due to an incident head injury. Table 1 describes the ten year cohort. The majority of the ten year cohort was male, comprising $68.7 \%$ of the total injured population. The overall ten year risk ratio for males compared to females was $2.21(95 \% \mathrm{CI}=2.18-2.24)$ (Figure 1). The average age for the ten year period for the entire cohort was $34.3 \pm 23.0$, for males, the average age was $32.4 \pm 20.5$ and for females, $38.0 \pm 26.8$. Figure 2 displays the five year age breakdown of the cohort by sex. For males, the age group with the most injuries was the 15-19 year olds and this was followed by the 20-24 year olds. For females the age group with the most injuries was also the 15-19 year olds, although the group with the second highest number of injuries was the 10-14 year olds.

The year with the greatest number of admissions due to a head injury was 1991/92 with a raw injury number of 5798. The year with the lowest raw number of head injuries was 2000/01, with 3535 . Of the people admitted for a head injury in this ten year period, $4.3 \%(n=2119)$ died as a result of this injury. On average, there were 211 deaths per year. The year with the most deaths due to a head injury was $1999 / 00$ with $6.4 \%$ of the head injury admissions resulting in a death.

The most common head injury diagnosis was an "Intracranial" injury and these comprised $52.4 \%$ of all head injury diagnoses. Of these (25569), 45\% (11529) were identified by the codes 854.0 and 854.1 indicating "Intracranial Injuries" including: brain injury NOS, cavernous sinus and intracranial injury, and 8925 (34.9\%) were coded as concussions (850.0). Over the ten year period, admissions due to concussion dropped from $n=1406$ in 1990/91 to $n=0$ in $1999 / 00$ and $2000 / 01$. While admissions due to other intracranial injuries stayed consistent with $n=1361$ in 1990/91 to $n=922$ in 2000/01. The second and third most noted diagnoses were "Fractured Facial Bones" (32.0\%) and "Fractured Skull" (10.4\%).

The most noted cause or mechanism of injury was "Falls" accounting for $31.1 \%$ of the total injuries, followed by "Motor Vehicle Traffic" (26.1\%) and "Intentional / Interpersonal Violence" (17.8\%).

The greater part of the head injury hospital admissions came from the lowest socioeconomic quintile with $23.1 \%$; this was followed by the second lowest quintile with $19.6 \%$. The middle, high and the highest economic quintiles had very similar proportions of the data, with $17.7 \%, 17.6 \%$, and $16.2 \%$ respectively.

The British Columbia Health Authority with the most admissions was the Fraser Health Authority with $26.8 \%$ of the over all admissions, while Vancouver Coastal had the least with only $14 \%$ of the overall admissions.

The age standardized rates are indicated in Table 2 and displayed in Figure 1. The year with the highest total age standardized rate was 1991/92 (174.18/100 000) and this was followed by 1992/93 (159.22/100 000). Males had the highest 


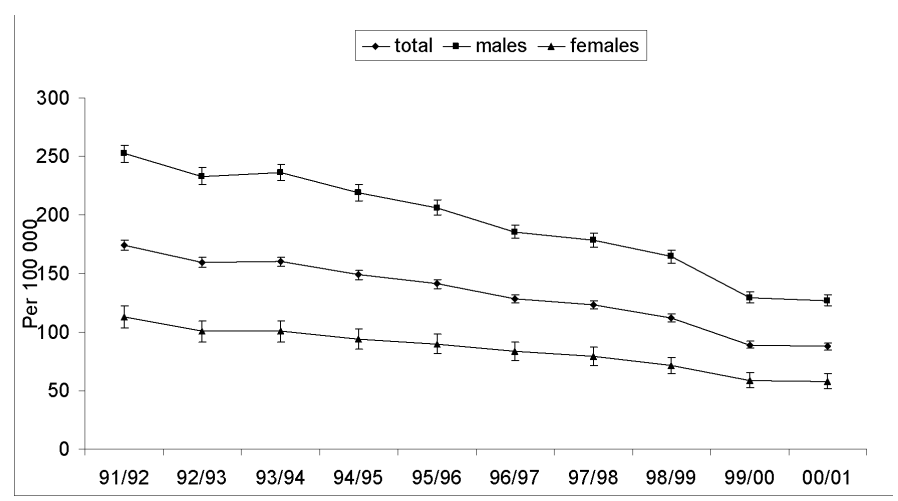

Figure 1: Head injury rates by fiscal year, based on hospital utilization data.

rates of injury ranging from $244.86 / 100000$ in 1991/92 to $122.09 / 100000$ in $2000 / 01$. Males were consistently two times at greater risk for injury than females for all ages.

Health care utilization was measured using length of hospital stay, presence of ICU admission, and mean length of ICU stay. The mean length of stay (LOS) for the entire cohort was $7.4( \pm$ 19.6) days. The mean LOS for each year is presented in Table 3. The year with the longest mean LOS was 2000/01 with 8.0 days, while the year with the shortest mean LOS was 1994/95 at 5.5 days. The mean LOS by diagnosis is presented in Table 4 . The diagnosis with the longest mean length of stay was "Fractured
Skull" (14.2 days) while the shortest mean length of stay was for "Fractured Facial Bones" (3.3 days). The top five commonly cited nature of injury codes (E-codes) had mean length of stay times ranging from 12.2 days for "Motor Vehicle Traffic" incidents to 2.8 days for "Other". The "Other" category includes E-codes that refer to unspecified fractures, accidents caused by explosive materials, electric currents, or explosions of pressure vessels. A comparison of the mean length of stay for each of the ten years found a significant difference, $(\mathrm{p}<.001)$.

For the total ten year cohort of $48,753,10.0 \%(n=4870)$ were transferred to an intensive care unit. For this $10 \%$, the mean length of stay was 5.5 days $( \pm 7.9)$. When the mean differences for the ten year period were compared, the analysis indicated that there was a significant increase in the mean length of stay over the ten year period, $(\mathrm{p}<.001)$.

\section{Discussion}

The importance of the impact of traumatic brain injury and the burden of this injury is now widely recognized. In the United States, the CDC reports that over 1.5 million Americans sustain a traumatic brain injury every year. ${ }^{2,14}$ Many researchers refer to head injuries as a 'silent epidemic', as the results of these injuries are not often visible and potentially lead to long term disability. ${ }^{12}$ There is ample evidence that even a mild head injury can have a negative impact on function and can contribute to long-term problems, in particular, depression, anxiety, and increased suicide attempts. ${ }^{12,15-21}$ Additonally, symptoms associated with mild head injuries or post-concussive syndrome (headache, fatigue, dizziness, irritability, impaired memory, and/or

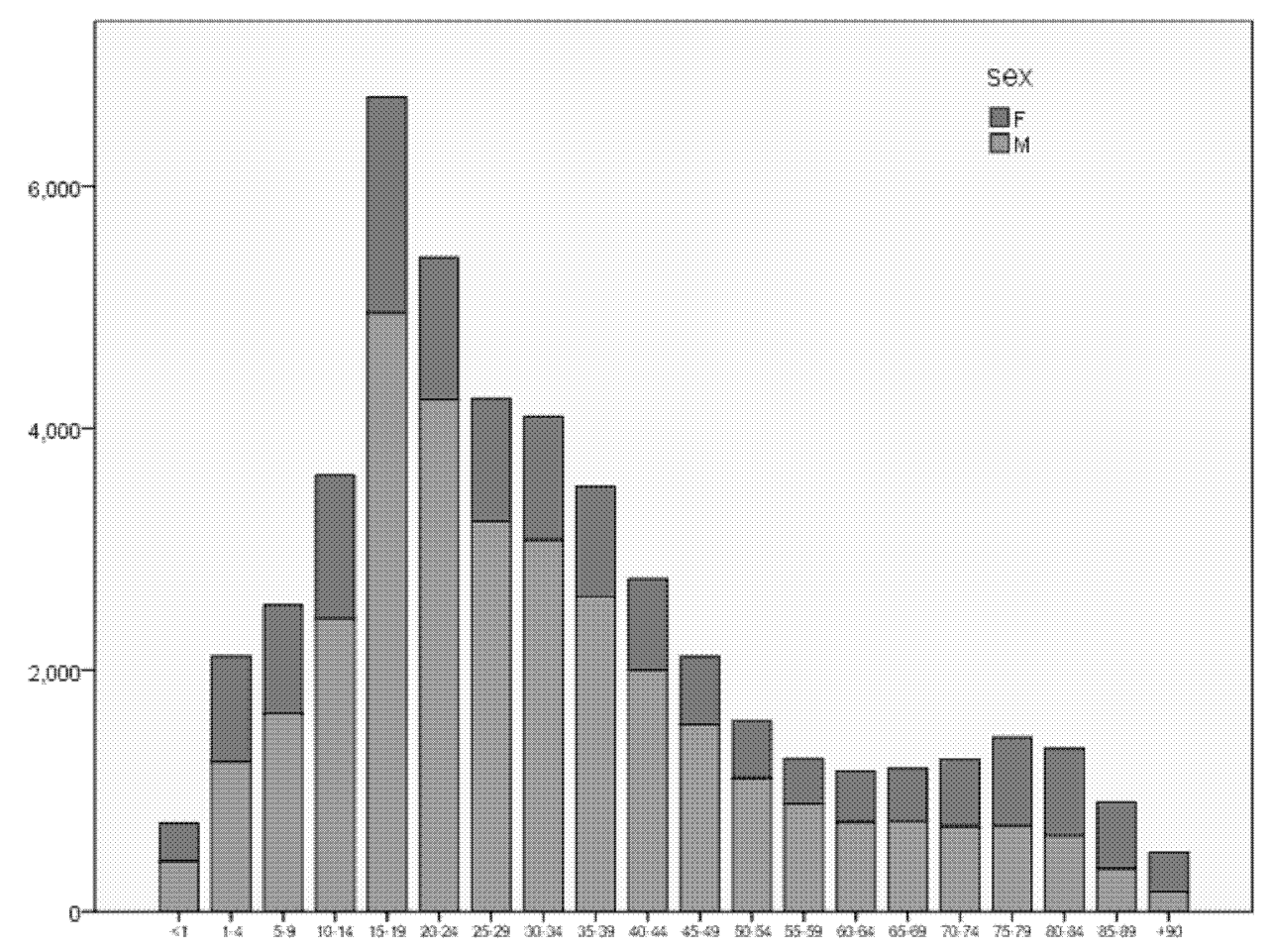

Figure 2: Age categories by sex. 
Table 2: Age standardized rates of head injury: 1991-2001

\begin{tabular}{l|l|l|l|l|l}
\hline & \multicolumn{3}{|l|}{ Rate per 100000} & Risk Ratio & \\
\hline Fiscal Year & Total & Female & Male & Males to Females & $95 \% \mathrm{Cl}$ \\
\hline $91 / 92$ & 174.18 & 107.98 & 244.86 & 2.15 & $2.06-2.24$ \\
\hline $92 / 93$ & 159.22 & 96.02 & 226.04 & 2.24 & $2.14-2.34$ \\
\hline $93 / 94$ & 160.03 & 96.12 & 228.90 & 2.24 & $2.15-2.34$ \\
\hline $94 / 95$ & 148.85 & 89.52 & 212.18 & 2.24 & $2.16-2.36$ \\
\hline $95 / 96$ & 140.97 & 85.73 & 199.94 & 2.22 & $2.13-2.32$ \\
\hline $96 / 97$ & 128.71 & 79.48 & 179.76 & 2.19 & $2.09-2.29$ \\
\hline $97 / 98$ & 123.44 & 75.67 & 172.65 & 2.21 & $2.11-2.32$ \\
\hline $98 / 99$ & 112.33 & 68.01 & 158.92 & 2.24 & $2.13-2.35$ \\
\hline $99 / 00$ & 89.13 & 55.50 & 124.62 & 2.15 & $2.04-2.27$ \\
\hline $00 / 01$ & 87.68 & 54.93 & 122.09 & 2.12 & $2.01-2.24$ \\
\hline
\end{tabular}

concentration) can persist for several months after the injury, affecting the ability to function at one's previous level. ${ }^{22,23}$

This study is an attempt to find a greater understanding about the public heath burden of head injuries in the $\mathrm{BC}$ population using a surveillance cohort. Surveillance is defined as the ongoing and systematic collection of data and the analysis and use of the data. ${ }^{14}$ It is now widely accepted that designing, implementing, and evaluating prevention strategies and using surveillance data to evaluate prevention programmes could substantially reduce the number of injuries and associated costs. ${ }^{1,3,24}$ The implementation of trauma surveillance systems has helped to decrease the overall incidence of severe traumatic brain injury in Canada. ${ }^{6}$

This population based surveillance cohort study sought to describe incidence of head injury cases in British Columbia, Canada. We found that the overall incidence of head injuries is decreasing. We speculate that admissions decreased rather then incidence of head injuries. Throughout the 1990s in Canada there was a switch in health care policy that advocated lowering health care costs by reducing hospital admissions and having more services carried out by outpatient services and clinics. Our findings coincide with findings from a study examining outcomes after the regionalization of major surgical procedures in Alberta. Hamilton et al found there was a 15\% increased case volume in community based health care centres and although the median length of hospital stay decreased, death rates remained unchanged. ${ }^{25,26}$

The data for this study was a linkage between two relevant administrative data sets in order to investigate the incidence of head injuries in the province of British Columbia. Administrative data can be a highly relevant and rich source of information to be used for both research and health policy decision making. One common criticism of administrative data is that they may be subject to selection bias as there may be measurement error related to factors including: diagnosis, coding, and reporting of injury that could potentially lead to over estimation through the inclusion of false positive cases ${ }^{27}$ For this study we maintain that the use of diagnosis codes as a source of case ascertainment is highly relevant. The CDC states that the use of these codes is critical to collecting quality TBI surveillance data. ${ }^{7}$ Initially, we used only the criteria defined by the CIHI, but due to limitations and confusion about case
Table 3: Mean length of stay for health care utilization variables (1991-2001)

\begin{tabular}{l|l|l|l}
\hline Fiscal Year & $\begin{array}{l}\text { Total LOS } \\
\text { mean }(\mathrm{sd})\end{array}$ & $\begin{array}{l}\text { \% admitted to ICU } \\
(\mathrm{n})\end{array}$ & $\begin{array}{l}\text { LOS in ICU } \\
\text { Mean }(\mathrm{sd})\end{array}$ \\
\hline $1991 / 92$ & $7.2(21.7)$ & $8.2(478)$ & $3.3(3.3)$ \\
\hline $1992 / 93$ & $7.5(21.2)$ & $9.1(498)$ & $3.5(3.6)$ \\
\hline $1993 / 94$ & $7.6(22.5)$ & $10.0(560)$ & $4.1(4.7)$ \\
\hline $1994 / 95$ & $5.5(12.5)$ & $10.3(553)$ & $3.8(3.9)$ \\
\hline $1995 / 96$ & $6.4(16.2)$ & $9.6(503)$ & $4.1(4.5)$ \\
\hline $1996 / 97$ & $7.3(19.7)$ & $9.9(489)$ & $4.3(4.8)$ \\
\hline $1997 / 98$ & $7.6(20.0)$ & $10.0(480)$ & $4.4(5.1)$ \\
\hline $1998 / 99$ & $6.8(15.5)$ & $10.8(479)$ & $4.4(4.8)$ \\
\hline $1999 / 00$ & $7.1(15.3)$ & $11.9(423)$ & $5.7(6.1)$ \\
\hline $2000 / 01$ & $8.0(18.0)$ & $11.5(407)$ & $6.5(7.0)$ \\
\hline Total & $7.4(19.6)$ & $10.0(4870)$ & $4.3(4.8)$ \\
\hline
\end{tabular}

LOS=Length of Stay

ascertainment as noted in our introduction, we felt it pertinent to look to the literature for a more thorough definition. In 1995, the CDC published Guidelines for Surveillance of Central Nervous System Injury. This document provides a standard clinical case definition of TBI (craniocerebral trauma, major and minor) that can be summarized as follows: "an occurrence of injury to the head (arising from blunt or penetrating trauma or from acceleration-deceleration forces) that is associated with

Table 4: Length of stay by diagnosis and E-codes

\begin{tabular}{|c|c|c|}
\hline Diagnosis Category & $\mathrm{N}^{*}$ & Mean LOS (sd) \\
\hline Intracranical (850.0-854.1) & 25409 & $8.5(21.2)$ \\
\hline $\begin{array}{l}\text { Fx Facial Bones (802.0-802.9, } \\
830.0)\end{array}$ & 15567 & $3.3(10.1)$ \\
\hline Fx Skull (800.0-801.9) & 5035 & $14.2(28.0)$ \\
\hline Head Injury NOS (959.01) & 1455 & $5.3(15.0)$ \\
\hline Other Skull Fxs (803.0-804.9) & 848 & $13.0(26.6)$ \\
\hline $\begin{array}{l}\text { Blood Vessels and Nerves } \\
\text { (including Optic) }(900.0-900.9 \text {, } \\
950.1-950.3,953.0-953.9)\end{array}$ & 196 & $14.0(29.5)$ \\
\hline \multicolumn{3}{|l|}{ Ecode Category } \\
\hline Falls & 15049 & $7.9(18.6)$ \\
\hline Motor Vehicle Traffic & 12626 & $12.2(26.3)$ \\
\hline Intentional/Violence & 8667 & $3.4(12.0)$ \\
\hline Other & 7086 & $2.8(11.5)$ \\
\hline Other Road & 2583 & $3.6(12.1)$ \\
\hline Motor Vehicle Nontraffic & 949 & $6.4(17.0)$ \\
\hline Suicide & 307 & $20.0(34.1)$ \\
\hline Nat/Environmental & 274 & $4.6(13.7)$ \\
\hline Transport (Water) & 242 & $8.2(20.3)$ \\
\hline Medical Misadventures & 158 & $24.9(37.1)$ \\
\hline Undetermined Intent & 118 & $12.0(23.3)$ \\
\hline Transport (Air) & 100 & $2.1(4.1)$ \\
\hline Late Effects of Accident & 87 & $13.9(29.0)$ \\
\hline Adverse Effects of Drugs & 69 & $15.7(29.3)$ \\
\hline Suffocation/Drowning & 58 & $15.0(40.6)$ \\
\hline Rail & 48 & $13.7(22.9)$ \\
\hline Legal Intervention & 15 & $5.9(10.5)$ \\
\hline Fire & 13 & $22.7(53.2)$ \\
\hline Operations of War & 2 & $4.5(3.5)$ \\
\hline
\end{tabular}

* (extreme outliers removed); Fx=Fractured/Fractures; NOS=Not Otherwise Specified 
symptoms or signs attributable to the injury, for example, decreased level of consciousness, amnesia, to other neurological or microphysical abnormalities, skull fracture, diagnosed intracranial lesions-or death". ${ }^{7}$ Additionally, these guidelines provide a clear standard case definition when using administrative data sets, and were incorporated into our study.

Additionally, when investigating head injuries it is particularly important to include the diagnosis of "Fractured Facial Bones". Research has noted that these are well documented surrogates for potential head injury including both major and minor traumatic brain injuries. We base this assumption on several findings in the research field of sports medicine and in particular, research pertaining to head injuries sustained in ice hockey. Sports injury researchers assert that a direct blow to the face may cause a force with translatory and rotational components. ${ }^{28}$ These "blows" to the face often result in significant rotational acceleration of the head and the brain. Additionally, they state that a blow directly to the chin may cause a translatory force which is transmitted from the chin through the lower jaw, through the temporo-mandibular joint at the base of the skull and then to the brain. These forces may also cause shock wave propagations through the brain, which may result in the cause of a traumatic brain injury. ${ }^{28}$

Furthermore, evidence has been found by Bishop that the three leading causes for MTBI in ice hockey included: a direct eccentric blow to the head, a direct blow to the face and a blow directed to the chin. Therefore, we feel that "Fractured Facial Bones" should be included as the nature of this injury would be directly related to some type of "blow" to the face. ${ }^{29}$

British Columbia is one of the most populated provinces in Canada. The province is divided into five regional health authorities with the central ministry setting province-wide goals, standards and performance agreements for health service delivery by the health authorities. The results of this study indicated that the health authority that sees the highest raw number of incident head injury cases was the Fraser Health Authority followed by the Interior Health Authority. This provides evidence that TBI is both an "Urban" and "Rural" phenomena, as Fraser Health Authority is generally considered a high density urban health authority while the Interior Health Authority is less dense and more "rural".

The relative risk when comparing males to females stayed consistent over the ten year period with males consistently being at twice the risk for TBI when compared to females. Although, the average age of individuals to experience a head injury was 34 , the age group with the most noted incidence of head injuries was the 15-19 years olds, followed by the 20-24 year olds. This finding is consistent with existing literature of the incidence of TBI and trauma in general. ${ }^{4,5,30-32}$

For the overall ten year cohort, the most commonly noted mechanism of injury was "Falls", followed by "Motor Vehicle Traffic", and then "Intentional". These three injury types are also the most commonly coded mechanisms of injury in trauma surveillance datasets. ${ }^{8-11}$ However, the finding that head injuries due to falls outnumbered those caused by motor vehicles is mostly likely indicative of this type of injury. Additionally, falls are often found to be the leading cause of hospitalizations..$^{8-11}$ Finally, when examining the socio-economic quintiles of our dataset we found that those in the lowest and second lowest quintile had the largest percentage of incident head injury cases.
This finding could reflect the higher risk taking behavior sometimes seen with this population, as well as greater exposure to risk due to environmental factors such as occupation and higher crime neighborhoods. ${ }^{4}$

\section{Strengths}

Population based cohorts studies are advantageous because they allow for comparisons to be made on an international level. The purpose of this study was to define the population at risk, identify incidence rates, and assess the utilization of health care for patients suffering from both mild and severe traumatic brain injuries in the population of British Columbia, Canada. We achieved this by using a population cohort analysis over a ten year period.

Additionally, our study used CDC and CIHI recommended ICD-9 codes that ensured concurrent head injury definitions across domains as well as the direct method of standardization. This method allows others to replicate our study and be able to make much needed comparisons of incidence rates and hospitalizations for head injuries across provinces.

Furthermore, this study was population based, with a sizeable case number and very little missing data with regard to external cause of injury and ICD-9 codes, therefore able to provide precise estimates of incidence rates.

\section{Limitations}

There are a few important limitations, however, that should be noted. One such limitation is that only hospitalizations were included as an indicator of incidence this may have underestimated the incidence rate for this type of injury. However, hospital admissions should capture the majority of serious cases requiring medical intervention.

Unfortunately, the severity of injury is not included in this dataset. As we noted, the mean length of stay was longer for patients with a "Fractured Skull". The category "Fractured Skull" includes both open and closed head injuries that involve subarachnoid, subdural, and extradual hemorrhages. Therefore, the longer length of stay for these types of injuries was not unexpected and the longer length of stay could potentially indicate severity.

This study is a first step in the epidemiological analysis of head injuries in BC, Canada. Further research is planned to link these data with the physician ambulatory care data, allowing us to include co-morbidity considerations and follow up care, thus improving our understanding of this serious public health challenge.

\section{REFERENCES}

1. Binder S, Corrigan JD, Langlois JA. The public health approach to traumatic brain injury: an overview of CDC's research and programs. J Head Trauma Rehabil. 2005;20(3):189-95.

2. Langlois JA, Sattin RW. Traumatic brain injury in the United States: research and programs of the Centers for Disease Control and Prevention (CDC). J Head Trauma Rehabil. 2005;20(3):187-8.

3. Langlois JA, Rutland-Brown W, Wald MM. The epidemiology and impact of traumatic brain injury: a brief overview. J Head Trauma Rehabil. 2006;21(5):375-8.

4. Yates PJ, Williams WH, Harris A, Round A, Jenkins R. An epidemiological study of head injuries in a UK population attending an emergency department. J Neurol Neurosurg Psychiat. 2006;77(5):699-701. 
5. Maegele M, Engel D, Bouillon B, Lefering R, Fach H, Raum M, et al. Incidence and outcome of traumatic brain injury in an urban area in Western Europe over 10 years. Eur Surg Res. 2007; 39(6):372-9.

6. Zygun DA, Laupland KB, Hader WJ, Kortbeek JB, Findlay C, Doig $\mathrm{CJ}$, et al. Severe traumatic brain injury in a large Canadian health region. Can J Neurol Sci. 2005;32(1):87-92.

7. Thurman DJ, Sniezek JE, Johnson DA, Greenspan A. Guidelines for surveillance of central nervous system injury. Atlanta, GA: US Department of Health and Human Services, Public Health Service, CDC. National Center for Injury Prevention and Control;1995.

8. National Trauma Registry Report: Major Injury in Canada, 20012002; 2003.

9. National Trauma Registry Report: Major Injury in Canada, 2002$2003 ; 2004$.

10. National Trauma Registry Report: Major Injury in Canada, 20032004; 2005

11. National Trauma Registry Report: Major Injury in Canada, 2004$2005 ; 2006$

12. Corrigan JD, Selassie AW, Lineberry LA, Millis SR, Wood KD, Pickelsimer EE, et al. Comparison of the Traumatic Brain Injury (TBI) Model Systems national dataset to a population-based cohort of TBI hospitalizations. Arch Phys Med Rehabil. 2007; 88(4):418-26.

13. Barell V, Aharonson-Daniel L, Fingerhut LA, Mackenzie EJ, Ziv A, Boyko V, et al. An introduction to the Barell body region by nature of injury diagnosis matrix. Inj Prev. 2002;8(2):91-6.

14. Langlois JA, Marr A, Mitchko J, Johnson RL. Tracking the silent epidemic and educating the public: CDC's traumatic brain injury-associated activities under the TBI Act of 1996 and the Children's Health Act of 2000. J Head Trauma Rehabil. 2005;20 (3):196-204

15. Bowen A, Neumann V, Conner M, Tennant A, Chamberlain MA. Mood disorders following traumatic brain injury: identifying the extent of the problem and the people at risk. Brain Inj. 1998;12 (3): $177-90$

16. Crisp R. Depression and occupational disability in five diagnostic groups: a review of recent research. Disabil Rehabil. 2007;29 (4):267-79.

17. Fann JR, Katon WJ, Uomoto JM, Esselman PC. Psychiatric disorders and functional disability in outpatients with traumatic brain injuries. Am J Psychiat. 1995;152(10):1493-9.

18. Moldover JE, Goldberg KB, Prout MF. Depression after traumatic brain injury: a review of evidence for clinical heterogeneity. Neuropsychol Rev. 2004;14(3):143-54.

19. Moore EL, Terryberry-Spohr L, Hope DA. Mild traumatic brain injury and anxiety sequelae: a review of the literature. Brain Inj. 2006;20(2):117-32.
20. Schoenhuber R, Gentilini M. Anxiety and depression after mild head injury: a case control study. J Neurol Neurosurg Psychiat. 1988;51(5):722-4.

21. Silver JM, Kramer R, Greenwald S, Weissman M. The association between head injuries and psychiatric disorders: findings from the New Haven NIMH Epidemiologic Catchment Area Study. Brain Inj. 2001;15(11):935-45.

22. Savola O, Hillbom M. Early predictors of post-concussion symptoms in patients with mild head injury. Eur $\mathrm{J}$ Neurol. 2003;10(2):175-81.

23. McClelland RJ. The postconcussional syndrome: a rose by any other name. J Psychosom Res. 1996;40(6):563-8.

24. Fletcher AE, Khalid S, Mallonee S. The epidemiology of severe traumatic brain injury among persons 65 years of age and older in Oklahoma, 1992-2003. Brain Inj. 2007;21(7):691-9.

25. Hamilton SM, Letourneau S, Pekeles E, Voaklander D, Johnston DW. The impact of regionalization on a surgery program in the Canadian health care system. Arch Surg. 2001;132(6):605-9.

26. Hamilton SM, Johnston WC, Voaklander DC. Outcomes after the regionalization of major surgical procedures in the Alberta Capital Health Region (Edmonton). Can J Surg. 2001;44(1): 51-8.

27. Van ED, Cote P, Beaton D, Hogg-Johnson S, Vidmar M, Kristman V. Capturing cases in workers' compensation databases: the example of neck pain. Am J Ind Med. 2006;49(7):557-68.

28. Biasca N, Simmen HP. Minor traumatic brain injury "mTBI" in hockey and other contacxt sports: Injury mechanisms at the macro and histological levels and prevention strategies. In: Pearsall DJ, Ashare AB, editors. Safety in ice hockey. 4th vol. West Conshohocken, PA: ASTM STP 1446. ASTM International; 2004. p. 98-131.

29. Bishop PJ. Protective equipment standards as a means of reducing injury risk. Sports Medicine \& Hockey; A summit for the NHL and beyond, American Orthopedic Society for Sports Medicine (AOSSM) and National Hockey League Team Physician Society (NHLTPS), Hilton Toronto, Canada. August 24-26, 2001, p. 57.

30. Rosso A, Brazinova A, Janciak I, Wilbacher I, Rusnak M, Mauritz W. Australian Severe TBI Study Investigators. Severe traumatic brain injury in Austria II: epidemiology of hospital admissions. Wien Klin Wochenschr. 2007;119(1-2):29-34.

31. Rutland-Brown W, Langlois JA, Thomas KE, Xi YL. Incidence of traumatic brain injury in the United States, 2003. J Head Trauma Rehabil. 2006;21(6):544-8.

32. Schneier AJ, Shields BJ, Hostetler SG, Xiang H, Smith GA. Incidence of pediatric traumatic brain injury and associated hospital resource utilization in the United States. Pediatrics. 2006;118(2):483-92. 